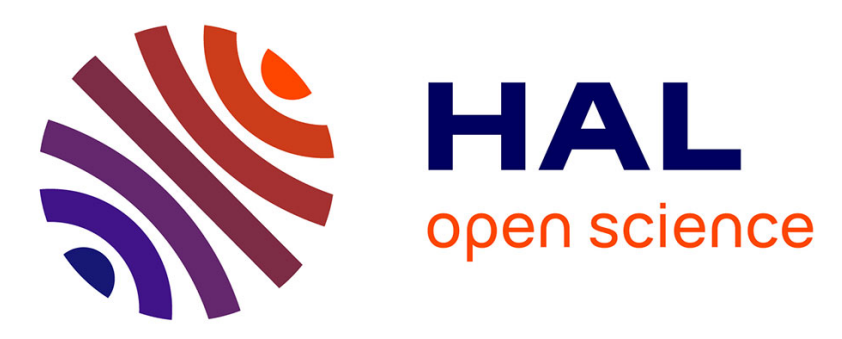

\title{
Thioglycerol-functionalized CdSe quantum dots detecting cadmium ions
}

\author{
Nassim Ben Brahim, Naim Bel Haj Mohamed, Mosaab Echabaane, Mohamed \\ Haouari, Rafik Ben Chaâbane, Michel Negrerie, Hafedh Ben Ouada
}

\section{- To cite this version:}

Nassim Ben Brahim, Naim Bel Haj Mohamed, Mosaab Echabaane, Mohamed Haouari, Rafik Ben Chaâbane, et al.. Thioglycerol-functionalized CdSe quantum dots detecting cadmium ions. Sensors and Actuators B: Chemical, 2015, 220, pp.1346-1353. 10.1016/j.snb.2015.07.049 . hal-01222839

HAL Id: hal-01222839

https://hal-polytechnique.archives-ouvertes.fr/hal-01222839

Submitted on 2 Nov 2015

HAL is a multi-disciplinary open access archive for the deposit and dissemination of scientific research documents, whether they are published or not. The documents may come from teaching and research institutions in France or abroad, or from public or private research centers.
L'archive ouverte pluridisciplinaire HAL, est destinée au dépôt et à la diffusion de documents scientifiques de niveau recherche, publiés ou non, émanant des établissements d'enseignement et de recherche français ou étrangers, des laboratoires publics ou privés. 


\section{Thioglycerol-functionalized CdSe quantum dots detecting cadmium ions}

Nassim Ben Brahim ${ }^{\mathrm{a}, *}$, Naim Bel Haj Mohamed ${ }^{\mathrm{a}}$, Mosaab Echabaane ${ }^{\mathrm{a}}$, Mohamed Haouari ${ }^{\mathrm{a}}$, Rafik Ben Chaâbane ${ }^{a}$, Michel Negrerie ${ }^{b,{ }^{*}}$ and Hafedh Ben Ouada ${ }^{a}$

${ }^{a}$ Laboratoire des Interfaces et Matériaux Avancés, Faculté des Sciences de Monastir, Bd. de l'Environnement, 5019 Monastir, Tunisia.

${ }^{\mathrm{b}}$ Laboratoire d'Optique et Biosciences, INSERM U1182, CNRS UMR7645, Ecole Polytechnique, 91128 Palaiseau, France.

*Corresponding authors.

E-mail: nassim.benbrahim.fsm@gmail.com. Phone: +21696400499

E-mail: michel.negrerie@polytechnique.fr. Phone: +331 69335052

\section{Keywords:}

CdSe quantum dots synthesis

Absorption spectroscopy

Electronic microscopy

Cadmium detection

Cation binding selectivity

\section{Highlights:}

- Water-soluble CdSe quantum dots capped with thioglycerol were synthesized.

- The absorption spectrum of the quantum dots dramatically changes upon cadmium binding.

- The presence of 17 other metal ions does not change the spectrum TG-CdSe quantum dots.

- The specificity of these CdSe thioglycerol-capped quantum dots for $\mathrm{Cd}^{2+}$ is very high. 


\section{ABSTRACT}

Water-soluble CdSe quantum dots (QDs) were synthesized using thioglycerol (TG) as the surface capping agent through a one-step process at low temperature $\mathrm{T}\left(100^{\circ} \mathrm{C}\right)$. The $\mathrm{CdSe}$ quantum dots were characterized by X-ray diffraction, Fourier transform infrared spectroscopy, transmission electron microscopy, UV-visible absorption and fluorescence spectroscopies. These measurements revealed that the TG-capped CdSe QDs possess a high crystalline quality with an average diameter in the range $2.5-2.8 \mathrm{~nm}$ and exhibit particular optical properties. The UV-visible absorption of CdSe QDs is enhanced by the addition of cadmium ions, with a simultaneous shift of the edge band $(400 \mathrm{~nm})$, while seventeen other tested metal cations have no effect on the absorption of QDs. Moreover, the binding of $\mathrm{Cd}^{2+}$ ions induces a quenching of the fluorescence emission of TG-CdSe QDs. At particular absorption wavelengths, the response is linearly proportional to the cadmium ions concentration ranging from 1.0 to $22 \mu \mathrm{M}$ with a detection limit of $0.32 \mu \mathrm{M}\left(37 \mu \mathrm{g} \cdot \mathrm{L}^{-1}\right)$. Based on these optical properties, the TG-CdSe QDs could be used as a highly selective probe for the detection of $\mathrm{Cd}^{2+}$ ions in aqueous solutions, a species highly toxic for cells. 


\section{Introduction}

Quantum dots (QDs), or semiconductor nanocrystals, are nowadays inestimable tools for fundamental studies as well as for potential applications such as biological probes $[1,2]$, fluorescent biosensor [3], light-emitting diodes (LEDs) [4] and solar cells [5]. Compared to conventional organic dyes, QDs possess unique properties including continuous absorption band, high photoluminescence (PL) quantum yields, photobleaching stability and tunability of the PL emission as a function of their size $[6,7]$. To date, two different routes have been reported for the synthesis of CdSe QDs, one being the most conventional organometallic approach $[8,9]$. As prepared, the CdSe nanocrystals have remarkable properties such as narrow width of the PL spectrum, high PL quantum yield, negligible photobleaching and excellent size homogeneity. This non-aqueous synthesis of capped QDs requires high temperature $\left(360{ }^{\circ} \mathrm{C}\right)[10]$, use of hydrophobic ligands [11] and solubilization strategies for their direct use in biological systems [12]. Alternatively, the aqueous synthesis route produces QDs with other advantages, including control of the size by the $\mathrm{pH}$ [13], water solubility, biological compatibility and stability [14,15]. However, the aqueous method has several drawbacks such as lower emission efficiency and a wider PL spectrum compared to the organic method. The design and synthesis of high quality water-soluble CdSe QDs disclosing specific and tunable properties to target biochemical analytes or biomolecular systems is a major issue, mainly reached by the choice of the functionalizing ligand coupled to CdSe. For example, Xue et al. reported highly luminescent water-soluble CdSe QDs prepared using thioglycolic acid as a capping ligand, which were covalently coupled to bacteria [16]. Alternatively, particular capped CdSe QDs could be prepared at the polarizable interface between water and 1,2-dichloroethane electrolyte solutions by an electrochemical method [17]. Triethanolamine-capped CdSe QDs were synthesized and used as fluorescent sensors for 
reciprocal recognition of mercury and iodide in aqueous solution [18] and CdSe nanocrystals incorporated in thin films were shown to interact with gazeous compounds such as benzylamine and triethylamine [19].

Here, we focus on the detection of cadmium ions, which is an extremely toxic metal widely found in plastics, fossil fuel combustion, phosphate fertilizers and other various chemicals [20]. These sources of cadmium often lead to contaminations in water, soil and eventually in food [21,22], causing serious environmental and health problems such as lung, prostate damage and kidney cancer [23,24]. In this study, we report the synthesis of thioglycerol-capped CdSe QDs and its interaction with cadmium in water. A facile preparation through a seed-assisted method at room temperature yields water-soluble CdSe QDs capped with thioglycerol (TG) which was used for the detection of $\mathrm{Cd}^{2+}$ ion by UV-Visible spectroscopy. These CdSe functionalized nanoparticles are characterized by a simple and lowcost preparation and a remarkably high selectivity for $\mathrm{Cd}^{2+}$ ions.

\section{Experimental procedures}

\subsection{Synthesis of TG-capped CdSe QDs}

We have followed the method previously described for the synthesis of CdS (cadmium sulfure) QDs capped with thiol derivatives [25] with some modifications. The chemicals were purchased from Sigma, Aldrich and Fluka. Briefly, an aqueous solution was obtained by mixing cadmium acetate dehydrate with thioglycerol (TG) as the stabilizer in deionized water with continuous stirring under nitrogen atmosphere. The $\mathrm{pH}$ of the resultant mixture was adjusted to 11.2 with $\mathrm{NaOH}$ solution. Separately, an aqueous solution of $\mathrm{Na}_{2} \mathrm{SeO}_{3}$ was prepared by introducing $\mathrm{SeO}_{2}$ into a $\mathrm{NaOH}$ solution and injected into the $\mathrm{pH}$-controled 
mixture of $\mathrm{Cd}^{2+}$ and stabilizer under vigorous stirring. The molar ratio $\mathrm{Cd}^{2+} / \mathrm{TG} / \mathrm{Se}^{2-}$ was set at $1 / 2 / 0.5$. Then, a solution of the reducing agent $\mathrm{NaBH}_{4}$ was injected with a syringe to the final solution under continuous stirring at $100{ }^{\circ} \mathrm{C}$ under $\mathrm{N}_{2}$ until the solution became light yellow. The TG capped CdSe quantum dots were obtained at this stage. The particles were extracted by precipitation in isopropanol. The solution was stirred for one hour and the precipitate was filtered then dried in a desiccator under vacuum. Fig. 1 summarizes the mechanism of formation of TG-capped CdSe QDs.

\subsection{Instrumentation}

X-ray diffraction (XRD) powder spectra were taken by XPERT PRO MPD Panalytical $\mathrm{X}$-ray generator using the $\mathrm{K} \alpha$ radiation of $\mathrm{Cu}$ at a wavelength of $1.542 \AA$ whose integration time was monitored to improve the signal-to-noise ratio. The diffraction angle $2 \theta$ was scanned in the range $20-70^{\circ}$ with a speed of $0.02 \%$. To detect the presence of TG on the surface of QDs Fourier-transform infrared (FTIR) spectra were measured using a Perkin Elmer FTIR spectrophotometer in the range $600-4000 \mathrm{~cm}^{-1}$. For FTIR analysis, powder samples of QDs were mixed with anhydrous potassium bromide $(\mathrm{KBr})$ pelletized.

For performing transmission electron microscopy (TEM) and energy dispersive X-ray (EDX) we have employed a JEOL 2010 FEG apparatus. Point EDX measurement was performed in scanning TEM mode.

\subsection{Optical measurements}

The UV-visible absorption spectra were collected either on a DR 5000 Hach Lange UV-vis spectrophotometer or a Shimadzu UV-1700. Fluorescence experiments were carried 
out on a Cary Eclipse spectrometer and spectra were collected in the range $400-800 \mathrm{~nm}$ with an excitation at $\lambda_{\mathrm{ex}}=360 \mathrm{~nm}$. Absorption and emission spectra were measured at room temperature $\left(20^{\circ} \mathrm{C}\right)$ by preparing a colloide solution of TG-CdSe quantum dots at $1.5 \mathrm{mg} \cdot \mathrm{L}^{-1}$ in $\mathrm{pH} 8.6$ buffer solution. To increase step-wise the concentration of cadmium or other transition metal ions from 1 to $24 \mu \mathrm{M}$, aliquots $(2-4 \mu \mathrm{L})$ of a stock solution $\left(10^{-3} \mathrm{M}\right)$ were added into a volume of $2 \mathrm{~mL}$ of CdSe QDs solution and mixed thoroughly. The final dilution factor (1.024) was negligible. The temperature-dependent measurements (Supplementary Material) were carried out with a home-designed 1-mm cell holder connected to a circulating bath. The optical path-length of the quartz cuvette was $1 \mathrm{~cm}$ for fluorescence and $1 \mathrm{~mm}$ for absorption measurements. The $\mathrm{pH}$ measurements were carried out with a Model Hanna $8519 \mathrm{~N} \mathrm{pH}-m e t e r$ and a combined glass electrode.

\section{Results and discussion}

\subsection{Characterization of TG-capped CdSe QDs by X-ray and electronic microscopy}

The XRD spectrum of TG-CdSe QDs (Fig. 2A) shows several diffraction peaks which appeared at $2 \theta=25.20^{\circ}, 41.90^{\circ}, 49.70^{\circ}, 67.96^{\circ}$ and $77.09^{\circ}$ corresponding to the diffraction planes (111), (220), (311), (331) and (422) respectively, according to the standard JCPDS data (card 19-0191) of bulk cubic CdSe. The peak broadening in the XRD pattern is due to a smaller size nanoparticles population. The average diameter $D$ of the CdSe nanoparticle can be estimated from the full width at half maximum (FWHM) of the (111) diffraction peak by means of Debye-Scherrer's [26] formula:

$D=0.9 \lambda / \beta \cos \theta$ 
where $\lambda$ is the wavelength of the incident X-rays, $\beta$ is the FWHM of the (111) peak in radians and $\theta$ is the Bragg diffraction angle. The average crystal size of the CdSe QDs thus estimated is $2.5 \mathrm{~nm} \pm 0.02 \mathrm{~nm}$.

An EDX analysis allowed to ascertain the composition of functionalized CdSe QDs whose spectrum (Fig. 2B) shows strong atomic peaks which originate from $\mathrm{Cd}$ and Se of QDs and peaks from thioglycerol ligand $(\mathrm{S}, \mathrm{C}$ and $\mathrm{O})$; nickel from the grid is also detected. The integration of $\mathrm{Cd}$ and $\mathrm{Se}$ signals indicates an average atomic percentage ratio $\mathrm{Cd} / \mathrm{Se}=$ 32.2/23.2 $=1.39$, showing that the synthesized QDs are enriched in cadmium.

Transmission electron microscopy (TEM) was employed to verify the morphology of the TG-CdSe QDs and to obtain a direct measurement of their size. The image (Fig. 3A) reveals a cluster of nanoparticles which are almost spherical and whose size population has a very small dispersion. The average diameter of nanoparticles was directly measured on high resolution TEM images (Fig. 3B) with the JEOL software and have a value of $\sim 2.5 \mathrm{~nm}$, remarkably close to the diameter calculated from the edge absorption spectrum and X-ray diffraction, which yielded $2.8 \mathrm{~nm}$ and $2.5 \mathrm{~nm}$, respectively.

\subsection{Characterization of TG-capped CdSe QDs by FT-IR and UV-visible spectroscopies}

The bonding between the stabilizer thioglycerol molecules and CdSe QDs was confirmed by FT-IR measurement in the range $600-4000 \mathrm{~cm}^{-1}$ (Fig. 4). The assignments of vibrational modes are given in Table 1 . This spectrum is similar to that of thioglycerol except for the absence of the S-H vibration band which appears usually at $2557 \mathrm{~cm}^{-1}$, indicating that thiolate functions are connected to the $\mathrm{Cd}^{2+}$ sites of the CdSe nanocrystals surface [27], as observed for core-shell CdSe/CdS QDs [28], implying that thiol-assisted capping of CdSe 
quantum dots has occurred. We can thus infer the presence of the organic layer coating on CdSe on the basis of the FTIR spectrum.

The UV-vis absorption spectrum is similar to that obtained for a film of TG-CdSe QDs synthesized via an organic route [29]. Both the absorption profile and first peak position (400 $\mathrm{nm} ; 3.01 \mathrm{eV}$ ) depend upon the particle size [30] and readily indicate the small size of these CdSe nanocrystals. The absorption spectra and fluorescence spectra (Fig. 5) of TG-CdSe QDs differ from that of bulk CdSe, with an absorption edge around $400 \mathrm{~nm}$ clearly blue shifted as compared to $\mathrm{CdSe}(1.74 \mathrm{eV}, 700 \mathrm{~nm})$. These values indicate an increase in the band gap of the QDs after TG treatment and witness about the quantum confinement effect which becomes more pronounced when the particle size becomes less or equal to the Bohr radius of the exciton in the corresponding bulk material [31].

The absorption edge threshold ( $\left.\lambda_{\text {thres }}\right)$ of the UV-vis absorption spectrum has been correlated with the particle diameter $(D)$ by Henglein's [32] whose experimental curve was described by an empirical relation [33]:

$D_{\text {CdSe }}=\left[1.338-0.002345 \lambda_{\text {thres }}\right]^{-1}$ in $\mathrm{nm}$

One must note that this relation, which is a fit of experimental data [33], is valide only in the range $\sim 1.5-6.5 \mathrm{~nm}$. The absorption edge threshold $\left(\lambda_{\text {thres }}\right)$ is defined as the wavelength at the inflection point of the sharply decreasing side absorption (crossing of the spectrum and its tangent), as described in Fig. 5B. This yielded the value $\lambda_{\text {thres }}=420 \pm 1 \mathrm{~nm}$, allowing to estimate the particles average diameter to be $2.83 \pm 0.02 \mathrm{~nm}$, very close to that calculated from the X-ray diffraction measurement $(2.5 \mathrm{~nm})$.

To estimate the band gap energy, the effective mass model can be used since the radius of the nanoparticles is lower than the Bohr radius of bulk exciton [34] (5.6 nm). If one neglects the energy of coulombic interaction between electron and hole which varies as $1 / R$, the band gap energy of QDs can be deduced from the following equation: 
$E_{g}^{e f f}=E_{g}+\left(h^{2} / 8 \mu R^{2}\right)$

where $R$ is the particle radius, $\mu$ the effective reduced mass, $E_{g}$ the bulk band gap energy $(1.74$ $\mathrm{eV}), E_{g}^{\text {eff }}$ the effective band gap energy and $h$ is the Plank's constant. Since the effective mass of electron is much smaller than that of the holes $\left(m_{e}^{\text {eff }}=0.13 m_{0}, m_{h}^{\text {eff }}=0.45 m_{0}\right)$, the charge carrier confinement mainly affects the energetic level of the electrons. By using the estimated particle size from absorption edge threshold $(2.83 \mathrm{~nm})$, the calculated effective band gap of CdSe QDs is $2.21 \mathrm{eV}$.

\subsection{Detection of cadmium ion and response of TG-capped CdSe nanoparticles}

The optical response of TG-CdSe QDs in buffer solution ( $\mathrm{pH} \mathrm{8.6)} \mathrm{has} \mathrm{been} \mathrm{evaluated}$ as a function of cadmium concentration (Fig. 6A). The absorbance of the first band, initially located at $400 \mathrm{~nm}$, increases with the addition of $\mathrm{Cd}^{2+}$ ions together with a shift of its position to $409 \mathrm{~nm}$. We also observed that the band located at $365 \mathrm{~nm}$ in the absence of $\mathrm{Cd}^{2+}$ disappears as the concentration increases, while the long-tailed absorption $(>450 \mathrm{~nm})$ increases. This latter change is not due to scattering from particles since the absorption increase at $450 \mathrm{~nm}$ is larger than at $300 \mathrm{~nm}$ and does not follow the proportionality with $1 / \lambda^{4}$. This long-tailed absorption increase was also observed in the case of functionalized CdS QDs interacting with $\mathrm{Co}^{2+}$ ions [35]. These spectral changes are a direct consequence of the metal ions interaction with TG-CdSe QDs. To visualize the real spectral evolution, we plotted the difference spectra at a given $\mathrm{Cd}^{2+}$ concentration minus the spectrum in the absence of $\mathrm{Cd}^{2+}$ (Fig. 6B) which reveals the appearance of an absorption band centered at $427 \mathrm{~nm}$ and the shift of the small band at $373 \mathrm{~nm}$ to $385 \mathrm{~nm}$.

The enhancement of absorbance of TG-CdSe QDs varies linearly at $427 \mathrm{~nm}$ with the $\mathrm{Cd}^{2+}$ ion concentration within the range $5.0-22 \mu \mathrm{M}$ with a slope of $\mathrm{K}=0.0278 \mu \mathrm{M}^{-1}$ (Fig. 7) 
yielding a limit of detection $\mathrm{LOD}=0.32 \mu \mathrm{M}\left(37 \mu \mathrm{g} \cdot \mathrm{L}^{-1}\right.$ of $\left.\mathrm{Cd}^{2+}\right)$ defined as $\mathrm{LOD}=3 \sigma / \mathrm{K}[36]$ where $\sigma$ is the standard deviation. This value is very similar to that measured for the detection of $\mathrm{Hg}^{2+}$ and $\mathrm{I}^{-}$by fluorescence quenching of triethanolamine-capped CdSe QDs [19] which, however, did not detect $\mathrm{Cd}^{2+}$, whereas the present TG-CdSe QDs do not interact with $\mathrm{Hg}^{2+}$, remarkably emphasizing the dependence of metal binding upon the nature of the capping chain.

The $\mathrm{pH}$ may affect the optical properties of functionalized QDs [37]. We indeed observed the $\mathrm{pH}$-dependence of the UV-vis absorption spectra of TG-CdSe QDs in the presence of $15 \mu \mathrm{M} \mathrm{Cd}^{2+}$ ions over the $\mathrm{pH}$ range $2.0-12$ (Fig. 7A). These measurements were expressed as the difference in absorbance of the TG-CdSe QDs in the presence and absence of $\mathrm{Cd}^{2+}$ at $400 \mathrm{~nm}$. The maximum response $\mathrm{A}-\mathrm{A}_{0}$ at $400 \mathrm{~nm}$ was obtained at $\mathrm{pH}=8.6$ (Fig. 7A) whereas for $\mathrm{pH}<6$ the absorbance was too weak and vanished at $\mathrm{pH}=2$. This may be attributed to the dissociation of the TG modified CdSe nanoparticles by protonation of the surface-binding thiolates [38]. On the other hand, for $\mathrm{pH}$ larger than 8.6, the absorbance decreases with a simultaneous precipitation of $\mathrm{Cd}(\mathrm{OH})_{2}$. Consequently, a standard $\mathrm{pH}$ of 8.6 was chosen for performing all experiments.

The response time of $\mathrm{Cd}^{2+}$ binding to TG-CdSe should depend on the concentration since the process can be described as a diffusion dependent receptor-ligand interaction. The kinetics of the absorbance change at $400 \mathrm{~nm}$ (Fig. 7B) after the addition of $15 \mu \mathrm{M} \mathrm{Cd}^{2+}$ to the TG-CdSe QDs solution shows that the induced change $\left(A-A_{0}\right)$ has reached $75 \%$ of its maximum after $90 \mathrm{~s}$. In order to standardize the measurements, we have chosen a 90-s response time after the addition of any metal cations at varying concentration to further characterize the TG-CdSe cation interaction.

The fluorescence intensity decreased when increasing the concentration of $\mathrm{Cd}^{2+}$ (Fig. 8) but without noticeable changes in the position of maximum and shape of the fluorescence 
spectrum. Consequently, the presence of $\mathrm{Cd}^{2+}$ gave rise to a quenching of the emission of QDs, which should be more pronounced than apparently observed if we consider the increase of the absorption coefficient at $360 \mathrm{~nm}$, the excitation wavelength. This apparent quenching could be partly linked to reabsorption of emission due to the increase of absorption at $570 \mathrm{~nm}$ and suggests a strong interaction between $\mathrm{Cd}^{2+}$ and TG-CdSe QDs [39]. The decrease of fluorescence observed here is at variance with the increase induced by $\mathrm{Cd}^{2+}(5-50 \mu \mathrm{M}$ range) binding to $\mathrm{CdSe} / \mathrm{ZnS}$ core/shell QDS caped with carnitine [40], suggesting different mechanisms for the two kinds of QDs.

As the thiol groups of TG are covalently bound to the QDs core, leaving the hydroxyl groups free, they can provide selective coordination sites for $\mathrm{Cd}^{2+}$ ions. On this basis, we propose in Fig. 9 a model for a working hypothesis where the cadmium cations interact with the hydroxyl groups of TG and forms cadmium oxide on the surface of CdSe QDs. We have retained the hypothesis of $\mathrm{Cd}^{2+}$ interacting with the non-ionized $\mathrm{OH}$ groups of $\mathrm{TG}$ rather than with their ionized form, because their $\mathrm{pKa}=9.43[41]$ and we have observed the maximal response for $\mathrm{pH}=8.6$.

We have also investigated the influence of the buffer composition, QDs concentration and temperature on the spectral properties and binding of $\mathrm{Cd}^{2+}$ to TG-CdSe QDs. The corresponding data are given in Supplementary Material. The various buffers used had no influence on the spectra whereas variations of the QDs concentration do not change the spectral shape and do not shift the bands. At large QDs concentration, a limited aggregation leads to an absorbance increase which is not proportional to the concentration. The absorbance edge of TG-CdSe QDs in the absence of $\mathrm{Cd}^{2+}$ has very slightly shifted as the temperature increased from $20{ }^{\circ} \mathrm{C}$ to $50{ }^{\circ} \mathrm{C}$ (Fig. S3). In the presence of $15 \mu \mathrm{M} \mathrm{Cd}^{2+}$, there is a decrease of the absorbance from 10 to $50{ }^{\circ} \mathrm{C}$ (Fig. S3B), while disclosing the same shift of the first band maximum position to $409 \mathrm{~nm}$ due to $\mathrm{Cd}^{2+}$ binding. This dependence is less 
pronounced between 10 and $20{ }^{\circ} \mathrm{C}$ and has a larger slope at $50{ }^{\circ} \mathrm{C}$. We readily assigned this decrease to the displacement of the equilibrium of $\mathrm{Cd}^{2+}$ interacting with the $\mathrm{OH}$ groups of TG, as it must be observed for any ligand-receptor system (Fig. S3C and D). This does not affect the capability of detecting $\mathrm{Cd}^{2+}$, but agrees with the origin of the absorption spectral changes assigned to $\mathrm{Cd}^{2+}$ binding.

\subsection{Influence of foreign metal Ions nature and specificity for $\mathrm{Cd}^{2+}$}

The presence of interfering ions may affect the optical response due to the $\mathrm{Cd}^{2+}-\mathrm{TG}$ CdSe interaction and we have therefore examined the selectivity of this binding. Fig. 10 shows the effect of particular metal cations at fixed concentration $(20 \mu \mathrm{M})$ on the absorption of QDs at $400 \mathrm{~nm}$. Saliently, only the addition of $\mathrm{Cd}^{2+}$ ions led to a drastic change of the absorbance whereas no spectral change was observed after the addition of the following metal cations alone: $\mathrm{K}^{+}, \mathrm{Na}^{+}, \mathrm{Li}^{+}, \mathrm{Pb}^{2+}, \mathrm{Ni}^{2+}, \mathrm{Mn}^{2+}, \mathrm{Mo}^{2+}, \mathrm{Hg}^{2+}, \mathrm{Zn}^{2+}, \mathrm{Ca}^{2+}, \mathrm{Mg}^{2+}, \mathrm{Fe}^{2+}, \mathrm{Cu}^{2+}, \mathrm{Co}^{2+}$, $\mathrm{Ba}^{2+}, \mathrm{Al}^{3+}$ and $\mathrm{Fe}^{3+}$. Moreover, the simultaneous presence of these cations with $\mathrm{Cd}^{2+}$ in solution of TG-CdSe QDs induced a similar increase of absorption as observed for $\mathrm{Cd}^{2+}$ alone (Fig. 10). Therefore, there is no competition between these common ions and $\mathrm{Cd}^{2+}$ for the binding to TG-CdSe QDs which can thus be used as a selective probe for the $\mathrm{Cd}^{2+}$ ions in aqueous solution at room temperature, whatever the absence or presence of other cations.

The binding properties of TG-CdSe QDs must be compared to those of other systems. Indeed, QDs made with different materials and capped with various ligands were shown to interact with various metal cations such as $\mathrm{Hg}^{2+}[19,42], \mathrm{Cu}^{2+}[43], \mathrm{Ba}^{2+}[44]$, and $\mathrm{Pb}^{2+}[45]$. When functionalized with 2-mercaptoethanol, CdSe QDs have been shown [44] to bind $\mathrm{Ba}^{2+}$ but not $\mathrm{Cd}^{2+}$ (no result was reported for $\mathrm{Fe}^{2+}$ and $\mathrm{Cu}^{2+}$, which are common interfering cations). Such a difference is remarkable and may provide a future direction to investigate the 
mechanism of selectivity in these systems. Not only the functionalization, but also the nature of QD itself determines the selectivity. For example, CdS QDs functionalized with carboxyl [35] is selective for $\mathrm{Co}^{2+}$, whereas CdTe QDs coupled with phenol-formaldehyde resin nanoparticles detected the binding of $\mathrm{Cu}^{2+}$ by means of fluorescence energy transfer.

We must note that neither CdSe QDs synthesized via the organic route at high $\mathrm{T}$ and functionalized with bovine serum albumin [46], nor CdS QDs functionalized with carboxyl [34], nor CdTe QDs capped with phenol-formaldehyde [43] can bind $\mathrm{Cd}^{2+}$ ions. The large number of cations that we tested here emphasizes the selectivity of the TG-CdSe sustem as a potential optical sensor for $\mathrm{Cd}^{2+}$ ions, whose molecular properties and mechanism at the origin of this selectivity remain to be investigated.

\section{Conclusion}

In the present work, TG-capped CdSe QDs were successfully synthesized in aqueous medium, in an easy and highly reproducible way, by using safe and low cost materials. These functionalized QDs selectively detect $\mathrm{Cd}^{2+}$ ions even in the presence of other cations which are physiologically relevant or can be present in water as pollutants. Under defined conditions $(\mathrm{pH}=7-9)$, this system shows sensitivity for $\mathrm{Cd}^{2+}$ ions in the concentration range $1.0-22$ $\mu \mathrm{M}$ with a detection limit of $0.32 \mu \mathrm{M}\left(37 \mu \mathrm{g} \cdot \mathrm{L}^{-1}\right)$. Together with a facile and low cost synthesis, its sensitivity and remarkable selectivity make the thioglycerol-capped CdSe a promising candidate for designing an optical tool to probe $\mathrm{Cd}^{2+}$ ions in solution, possibly to investigate its interaction with cultured cells.

\section{Acknowledgements}


N.B.B. acknowledges a travel research fellowship "Bourse d'Alternance" from the Tunisian

Government. We thank Mélanie Poggi (Laboratoire de Physique de la Matière Condensée, Ecole Polytechnique) for her expert assistance in recording TEM images.

\section{Appendix A. Supplementary data}

Supplementary data associated with this article can be found, in the online version, at http://dx.doi.org/10.1016/j.snb.2015.07.049

\section{Abbrevations}

TG-CdSe QDs: Cadmium-Selenium Quantum Dots functionalized with Thio-Glycerol capping. TEM: Transmission Electronic Microscopy. EDX: Energy Dispersive X-ray.

\section{References}

[1] Zheng Y., Gao S., Ying J. Y. Synthesis and cell-imaging applications of glutathione-capped CdTe quantum dots. Adv. Mater. 19 (2007) 376-380.

[2] Moussodia R. O., Balan L., Merlin C., Mustin C., Schneider R. Biocompatible and stable $\mathrm{ZnO}$ quantum dots generated by functionalization with siloxane-core PAMAM dendrons. J. Mater. Chem. 20 (2010) 1147-1155.

[3] Costa-Fernandez J. M., Pereiro R., Sanz-Medel A. The use of luminescent quantum dots for optical sensing. TrAC-Trends Anal. Chem. 25 (2006) 207-218.

[4] Lim J., Jun S., Jang E., Baik H., Kim H., Cho J. Preparation of highly luminescent nanocrystals and their application to light-emitting diodes. Adv. Mater. 19 (2007) 19271932. 
[5] Robel I., Subtamanian V., Kuno M., Kamat P. V. Quantum dot solar cells. Harvesting light energy with CdSe nanocrystals molecularly linked to mesoscopic $\mathrm{TiO}_{2}$ films. J. Am. Chem. Soc. 128 (2006) 2385-2393.

[6] Jamieson T., Bakhshi R., Petrova D., Pocock R., Imani M. Biological applications of quantum dots. Biomaterials 28 (2007) 4717-4732.

[7] Aldeek F., Balan L., Medjahdi G., Roques-Carmes T., Malval J.P., Mustin C., Ghanbaja J., Schneider R. Enhanced optical properties of core/shell/shell CdTe/CdS/ZnO quantum dots prepared in aqueous solution. J. Phys. Chem. C 113 (2009) 19458-19467.

[8] Murray C. B., Norris D. J., Bawendi M. G. Synthesis and characterization of nearly monodisperse CdE (E = S Se Te) semiconductor nanocrytallites. J. Am. Chem. Soc. 115 (1993) 8706-8715.

[9] Peng X. G. Green chemical approaches toward high-quality semiconductor nanocrystals. Chem. Eur. J. 8 (2002) 335-339.

[10] Qu L., Peng Z. A., Peng X. Alternative routes toward high quality CdSe nanocrystals. Nano Letters 1 (2001) 333-337.

[11] Khanna P. K., Singh N., Charan S., Lonkar S. P., Reddy A. S., Patil Y., Viswanath A. K. The processing of CdSe/polymer nanocomposites via solution organometallic chemistry. Mater. Chem. Phys. 97 (2006) 288-294.

[12] Yu W. W., Chang E., Drezek R., Colvin V. L. Water-soluble quantum dots for biomedical applications. Biochem. Biophys. Res. Commun. 348 (2006) 781-786.

[13] Spanhel L., Haase M., Weller H., Henglein A. Photochemistry of colloidal semiconductors .20. Surface modification and stability of strong luminescing CdS particles. J. Am. Chem. Soc. 109 (1987) 5649-4655. 
[14] Gaponik N., Talapin D. V., Rogach A. L., Hoppe K., Shevchenko E. V., Kornowski A., Eychmuller A., Weller H. Thiol-capping of CdTe nanocrystals: An aLernative to organometallic synthetic routes. J. Phys. Chem. B 106 (2002) 7177-7185.

[15] Rogach A. L., Kornowski A., Gao M. Y., Eychmuller A., Weller H. Synthesis and characterization of a size series of extremely small thiol-stabilized CdSe nanocrystals. J. Phys. Chem. B 103 (1999) 3065-3069.

[16] Xue X. H., Pan J., Xie H. M., Wang J. H., Zhang S. Fluorescence detection of total count of Escherichia coli and Staphylococcus aureus on water-soluble CdSe quantum dots coupled with bacteria. Talanta 77 (2009) 1808-1813.

[17] Su B., Fermin D. J., Abid J. P., Eugster N., Girault H. H. Adsorption and photoreactivity of CdSe nanoparticles at liquid/liquid interfaces. J. Electroanal. Chem. 583 (2005) 241247.

[18] Bin Shang Z., Wang Y., Jin W. J. Triethanolamine-capped CdSe quantum dots as fluorescent sensors for reciprocal recognition of mercury [II] and iodide in aqueous solution. Talanta 78 (2009) 364-369.

[19] Nazzal A. Y., Qu L., Peng X., Xiao M. Photoactivated CdSe nanocrystals as nanosensors for gases. Nano Letters 3 (2003) 819-822.

[20] Chaney R. L., Ryan J. A., Li Y. M., Brown S. L., McLaughlin M. J., Singh B. R. Eds. In Cadmium in soils and plants. Kluwer: Boston 1999, 219-246.

[21] Nordberg G. F., Herber R. F. M., Alessio L. Cadmium in the human environment, Oxford University Press: Oxford UK 1992.

[22] Friberg L., Elinger C. G., Kjellstrom T. Cadmium. World Health Organization Report: Geneva 1992.

[23] Goyer R. A., Liu J., Waalkes M. P. Cadmium and cancer of prostate and testis. BioMetals 17 (2004) 555-558. 
[24] Satarug S., Baker J. R Urbenjapol S., Haswell-Elkins M., Reilly P. E., Williams D. J., Moore M. R. A global perspective on cadmium pollution and toxicity in nonoccupationally exposed population. Toxicol. Lett. 137 (2003) 65-68.

[25] Bel Haj Mohamed N., Haouari M., Zaaboub Z., Nafoutti M., Hassen F., Maaref H., Ben Ouada $\mathrm{H}$. Time resolved and temperature dependence of the radiative properties of thiolcapped CdS nanoparticles films. J. Nanopart. Res. 16 (2014) 2242. DOI 10.1007/s11051013-2242-9

[26] Deng Z., Cao L., Tang F., Zou B. A new route to zinc-blende CdSe nanocrystals: mechanism and synthesis. J. Phys. Chem. B 109 (2005) 16671-16675.

[27] Tang H., Yan M., Zhang H., Xia M., Yang D. Preparation and characterization of watersoluble US nanocrystals by surface modification of ethylene diamine. Mater. Lett. 59 (2005) 1024-1027.

[28] Silva A. C. A., Da Silva S. W., Morais P. C., Dantas N. O. Shell thickness modulation in ultrasmall $\mathrm{CdSe} / \mathrm{CdS}_{\mathrm{x}} \mathrm{Se}_{1-\mathrm{x}} / \mathrm{CdS}$ core/shell quantum dots via 1-thioglycerol. ACS Nano 8 (2014) 1913-1922.

[29] Artemyev M. V., Woggon U., Jaschinski H., Gurinovich L. I., Gaponenko S. V. Spectroscopic study of electronic states in an ensemble of close-packed CdSe nanocrystals. J. Phys. Chem. B 104 (2000) 11617-11621.

[30] Jasieniak J., Smith L., van Embden J., Mulvaney P., Califano M. Re-examination of the Ssize-dependent absorption properties of CdSe quantum dots. J. Phys. Chem. C 113 (2009) 19468-19474.

[31] Cao Y. C., Wang J. H. One-Pot Synthesis of high-quality zinc-blende CdS nanocrystals. J. Am. Chem. Soc. 126 (2004) 14336-14337. 
[32] Spanhel L., Haase M., Weller H., Henglein A. Photochemistry of colloidal semiconductors. 20. surface modification and stability of strong luminescing CdS particles. J. Am. Chem. Soc. 109 (1987) 5649-5655.

[33] Moffitt M., Eisenberg A. Size control of nanoparticles in semiconductor-polymer composites. 1. control via multiplet aggregation numbers in styrene-based random ionomers. Chem. Mater. 7 (1995) 1178-1184.

[34] Brus L. E. Electron-electron and electron-hole interactions in small semiconductor crytallites: the size dependence of the lowest excited electronic state. J. Chem. Phys. 80 (1984) 4403-4409.

[35] Gore A. H., Gunjal D. B., Kokate M. R., Sudarsan V. P., Anbhule V., Patil S. R., Kolekar G. B. Highly Selective and sensitive recognition of cobalt[II] ions directly in aqueous solution using carboxyl-functionalized $\mathrm{CdS}$ quantum dots as a naked eye colorimetric probe: applications to environmental analysis. ACS Appl. Mater. Interfaces 4 (2012) $5217-5226$.

[36] Chen J., Zheng A., Gao Y., He C., Wu G., Chen Y., Kai X., Zhu C. Functionalized US quantum dots-based luminescence probe for detection of heavy and transition metal ions in aqueous solution. Spectrochimica Acta A 69 (2008) 1044-1052.

[37] Skoog D. A., Holler F. J., Nieman T. A. Principles of instrumental analysis $7^{\text {th }}$ ed. Saunders College Philadelphia 1998 601-608.

[38] Biju V., Makita Y., Sonoda A., Yokoyama H., Baba Y., Ishikawa M. Temperaturesensitive photoluminescence of CdSe quantum dot clusters. J. Phys. Chem. B 109 (2005) 13899-13905.

[39] Lakowicz J. R., Gryczynski I., Gryczynski Z., Murphy C. J. Luminescence spectral properties of CdS nanoparticles. J. Phys. Chem. B 103 (1999) 7613-7620. 
[40] Li H., Zhang Y., Wang X. L-Carnitine capped quantum dots as luminescent probes for cadmium ions. Sens. Actuators B 127 (2007) 593-597.

[41] Xu S., Wang C., Zhang H., Wang Z., Yang B., Cui Y. pH-sensitive photoluminescence for aqueous thiol-capped CdTe nanocrystals. Nanotechnology 22 (2011) 315703.

[42] Chen B., Ying Y., Zhou Z. T., Zhong P. Synthesis of novel nanocrystals as fluorescent sensors for $\mathrm{Hg}^{2+}$ ions. Chem. Letters 33 (2004) 1608-1609.

[43] Yang P., Zhao Y., Lu Y., Xu Q. Z., Xu X. W., Dong L., Yu S. H. Phenol formaldehyde resin nanoparticles loaded with CdTe quantum dots: a fluorescence resonance energy transfer probe for optical visual detection of copper(II) ions. ACS Nano 5 (2011) 2147-2154.

[44] Mahmoud W. E. Functionalized ME-capped CdSe quantum dots based luminescence probe for detection of $\mathrm{Ba}^{2+}$ ions. Sens. Actuators B 164 (2012) 76-81.

[45] Wu H., Liang J., Han H. A novel method for the determination of $\mathrm{Pb}^{2+}$ based on the quenching of the fluorescence of CdTe quantum dots. Microchim. Acta 161 (2008) 81-86.

[46] Liang J.-G., Ai X.-P., He Z.-K., Pang D.W. Functionalized CdSe quantum dots as selective silver ion chemodosimeter. Analyst 129 (2004) 619-622. 


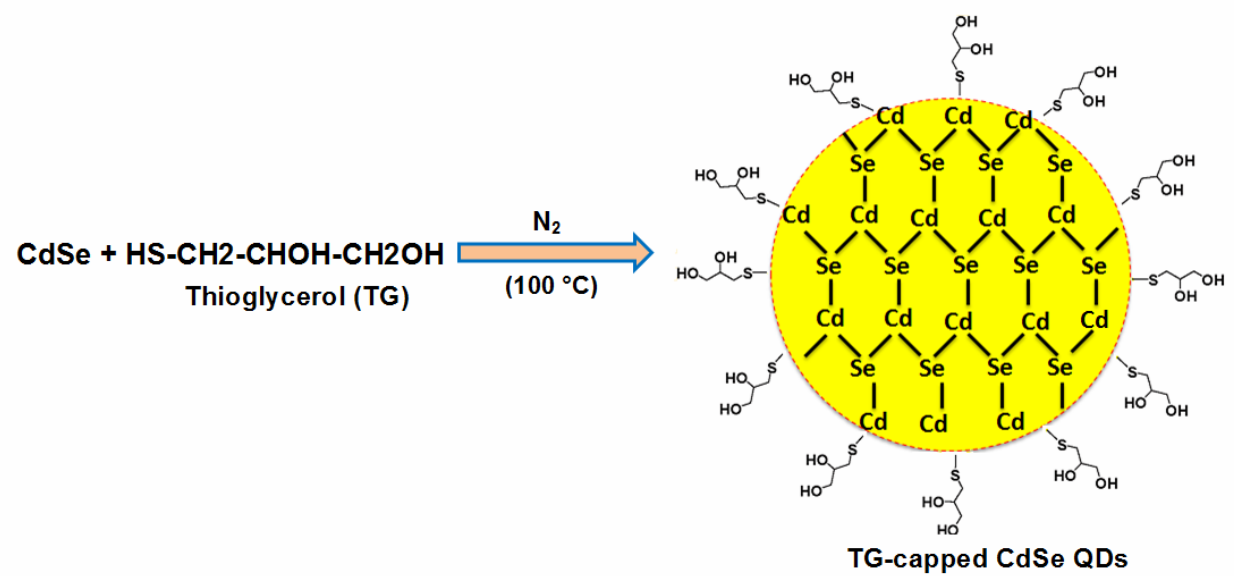

Fig. 1. Summary of TG-capped CdSe QDs synthesis via the aqueous route.

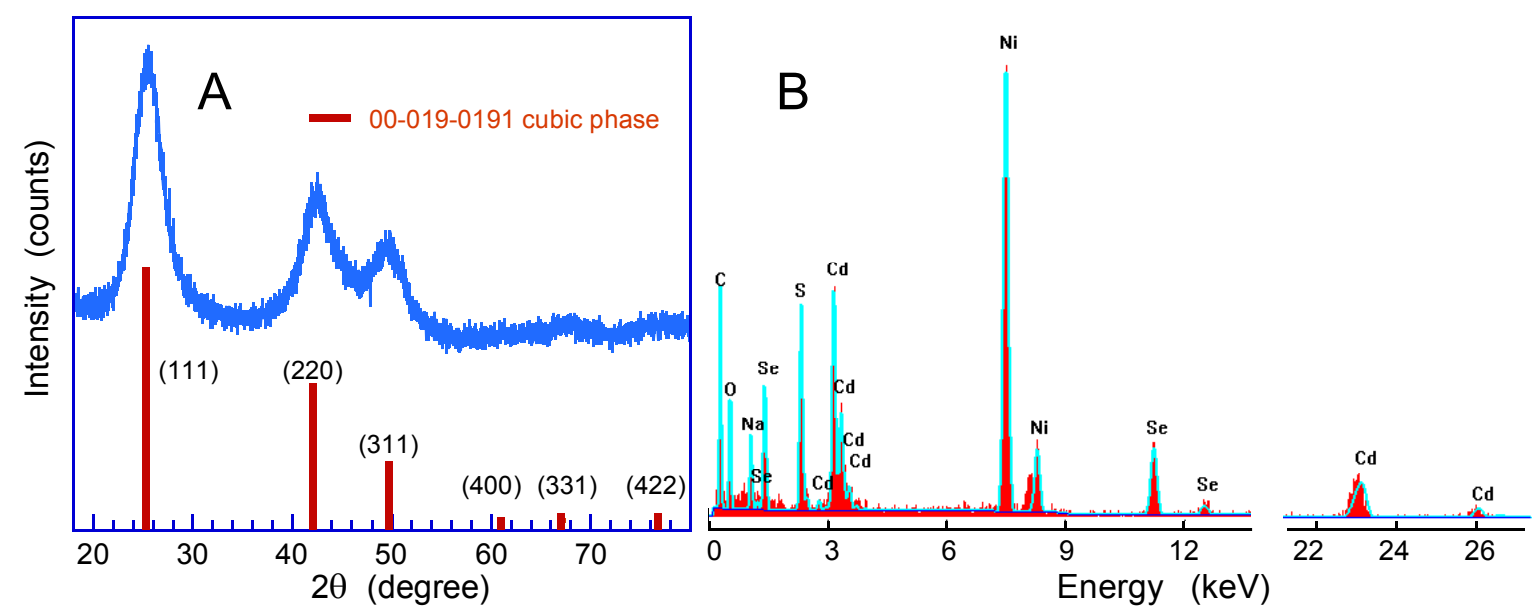

Fig. 2. (A) X-ray diffraction pattern for the TG-CdSe QDs. The positions of the corresponding cubic phases are indicated. (B) The EDX spectrum of TG-CdSe QDs and the reference atomic pattern are displayed in red and blue, respectively. 


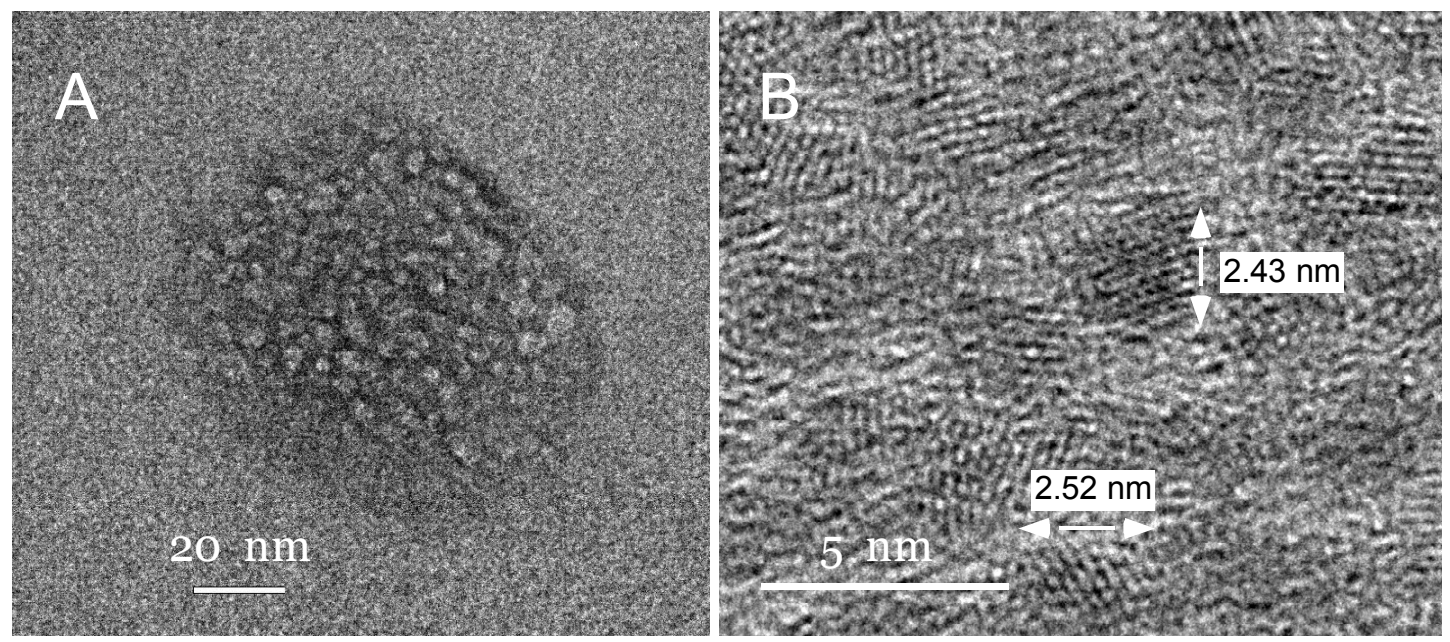

Fig. 3. (A) TEM image of a cluster of TG-CdSe QDs. (B) High resolution and large magnification ( $\times 600$ 000) image of individual TG-CdSe nanoparticles whose size was estimated by using the software DigitalMicrograph (Jeol).

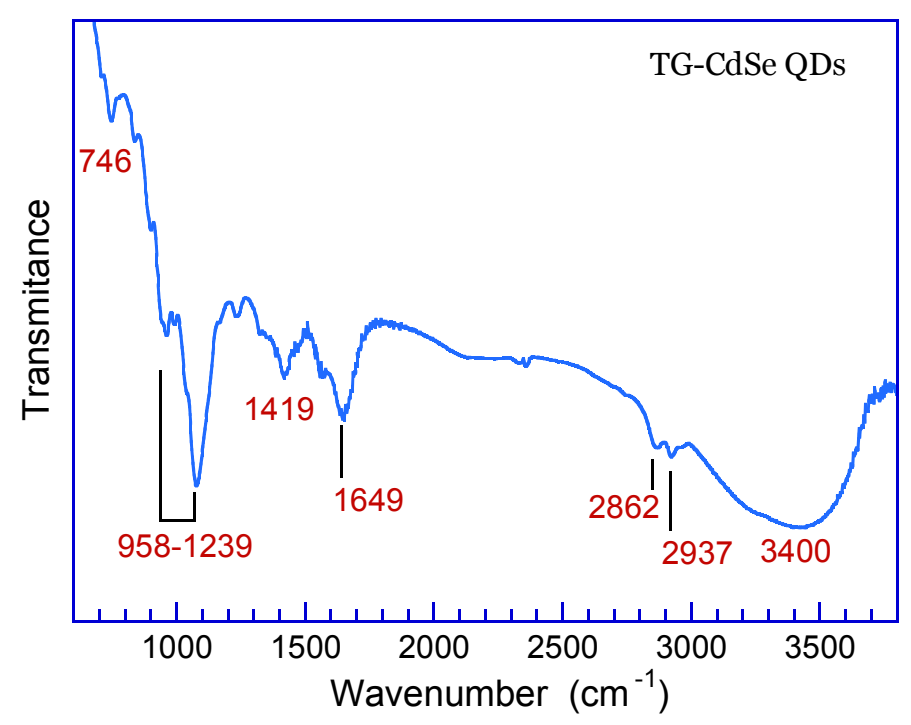

Fig. 4. Fourier transform infrared spectrum of TG-CdSe QDs mixed with anhydrous KBr. The band assignments are indicated in Table 1. 
Table 1. Assignment of the bands in the FT-IR spectrum of TG-CdSe QDs.

\begin{tabular}{|l|l|}
\hline Wavenumber $\left(\mathbf{c m}^{-1}\right)$ & Assignment \\
\hline 746 & Cd-Se bond stretching \\
\hline 958,1083 and 1239 & C-C stretching modes \\
\hline 1419 & C-H stretching mode \\
\hline 1649 & O-H bending mode of water \\
\hline 2862 & C-H stretching mode \\
\hline 2937 & $\mathrm{CH}_{2}$ symmetric stretching \\
\hline 3400 & O-H stretching mode \\
\hline
\end{tabular}



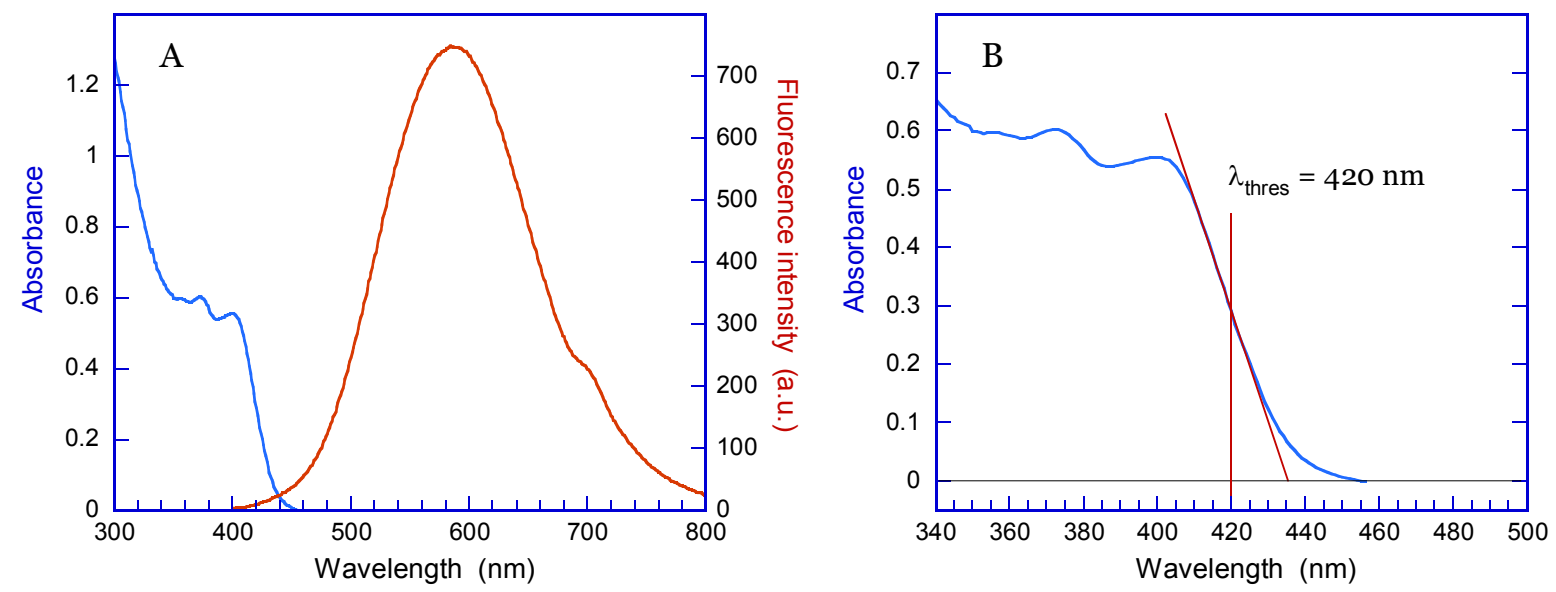

Fig. 5. (A) UV-visible absorption and fluorescence spectra of functionalized TG-CdSe QDs in aqueous solution. (B) Absorption edge threshold used for estimating the diameter of TG-CdSe QDs according to Henglein's emprirical relation.
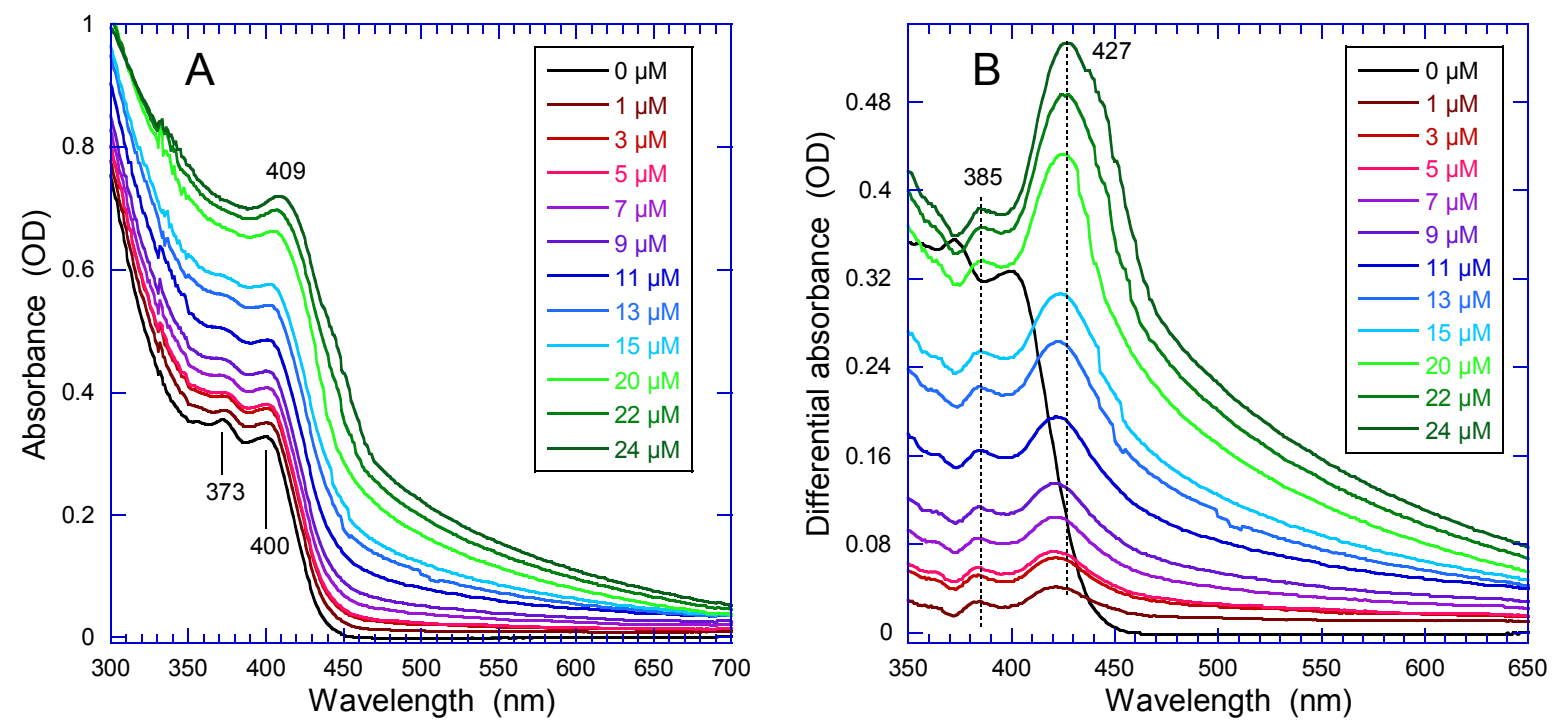

Fig. 6. (A) UV-vis absorption spectra of the TG-CdSe QDs $\left(5 \times 10^{-4} \mathrm{M}\right)$ solution with various concentrations of $\mathrm{Cd}^{2+}$ ions at equilibrium. (B) Difference absorption spectra at increasing $\mathrm{Cd}^{2+}$ concentration minus the spectrum of TG-CdSe QDs in absence of $\mathrm{Cd}^{2+} \cdot \mathrm{pH}=8.6$. 

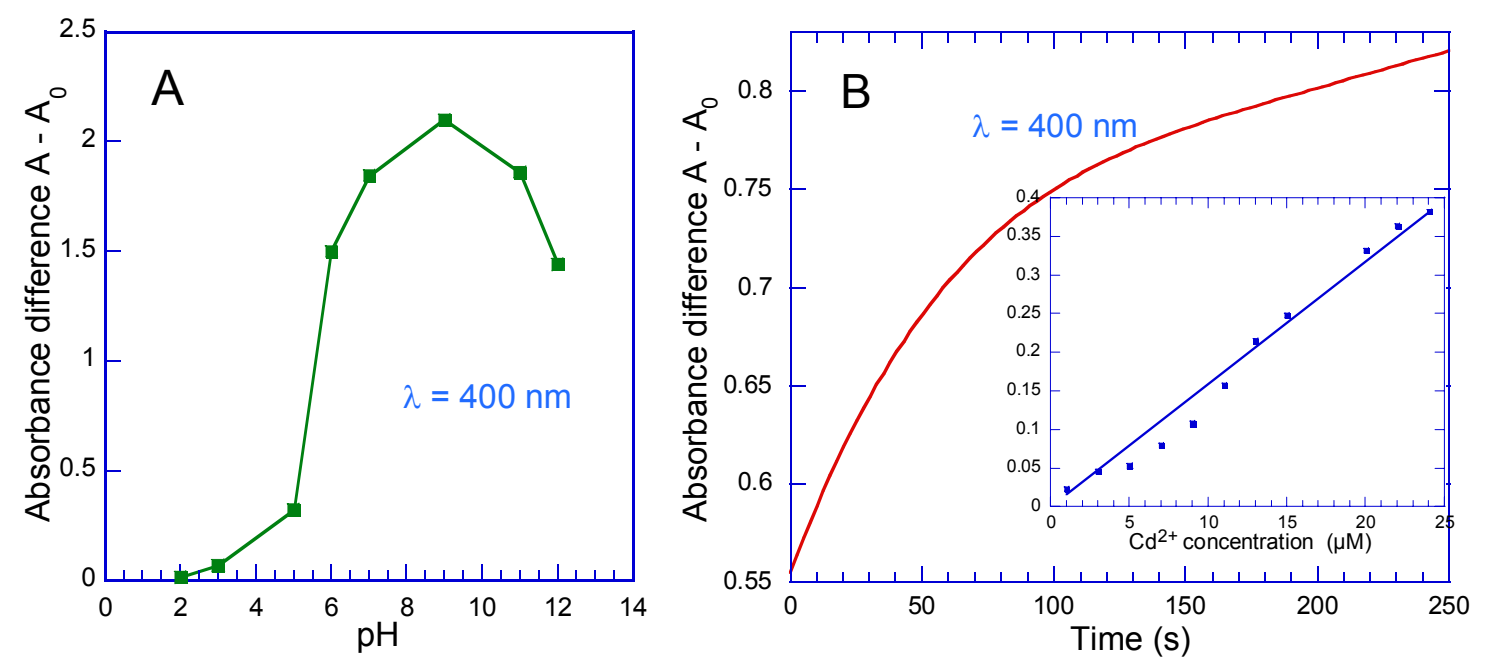

Fig. 7. (A) pH-dependent changes of the absorbance difference at $400 \mathrm{~nm}$ of the TG-CdSe QDs $\left(5 \times 10^{-4} \mathrm{M}\right)$ solution in the presence $\mathrm{Cd}^{2+}$ ions $(15 \mu \mathrm{M})$. (B) Kinetics of the absorption response at $400 \mathrm{~nm}$ of the TG-CdSe QDs $\left(5 \times 10^{-4} \mathrm{M}\right)$ solution at $\mathrm{pH}=8.6$ mixed with $\mathrm{Cd}^{2+}$ ions $(15 \mu \mathrm{M})$. Inset: dependence of $\left(\mathrm{A}-\mathrm{A}_{0}\right)$ at $400 \mathrm{~nm}$ on the $\mathrm{Cd}^{2+}$ ions concentration, with a linear fit (correlation coefficient $=0.9923$ ). $\mathrm{A}$ and $\mathrm{A}_{0}$ are the absorbance of TG-CdSe QDs in presence and in absence of $\mathrm{Cd}^{2+}$ ions respectively.

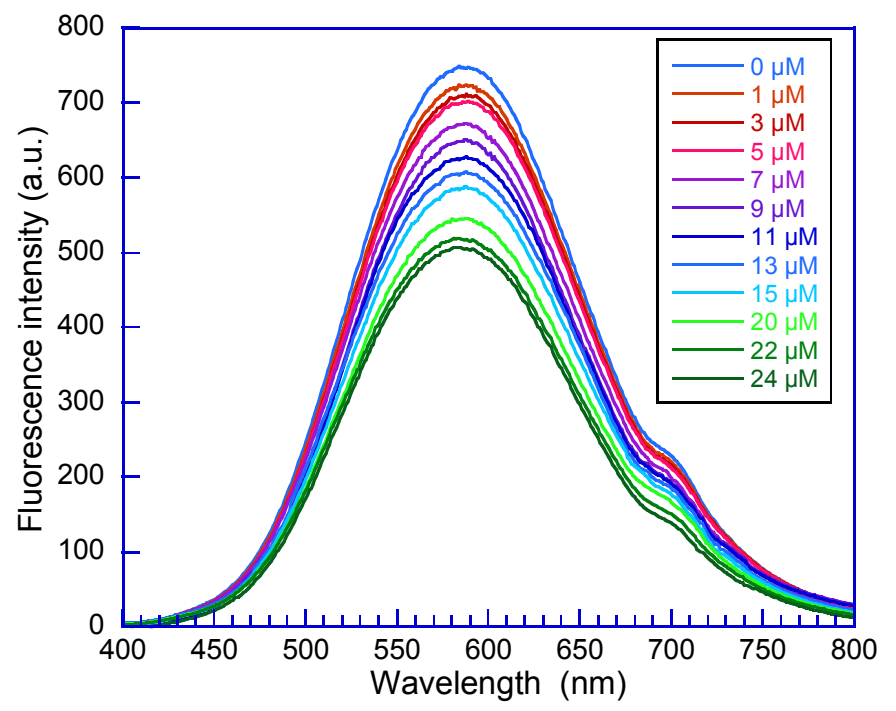

Fig. 8. Evolution of the fluorescence spectrum of TG-CdSe QDs $\left(5 \times 10^{-4} \mathrm{M}\right)$ after the addition of increasing concentration of $\mathrm{Cd}^{2+}$. Excitation wavelength is $360 \mathrm{~nm}$. 

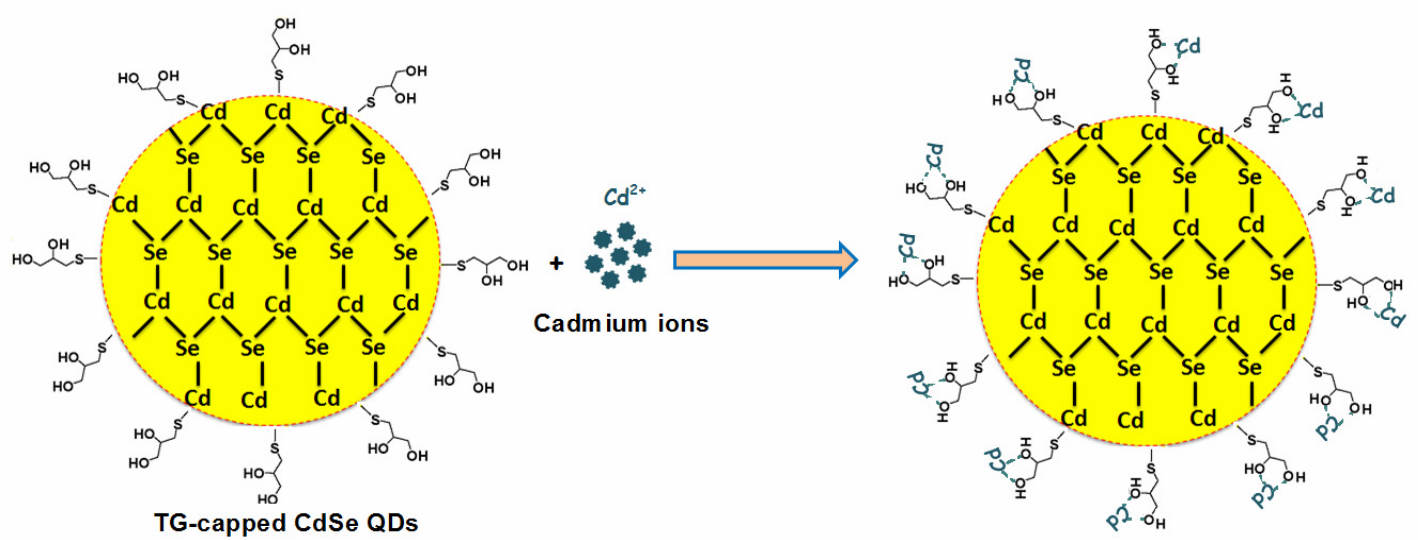

Fig. 9. Proposed mechanism of interaction between TG-capped CdSe QD and $\mathrm{Cd}^{2+}$ ions.

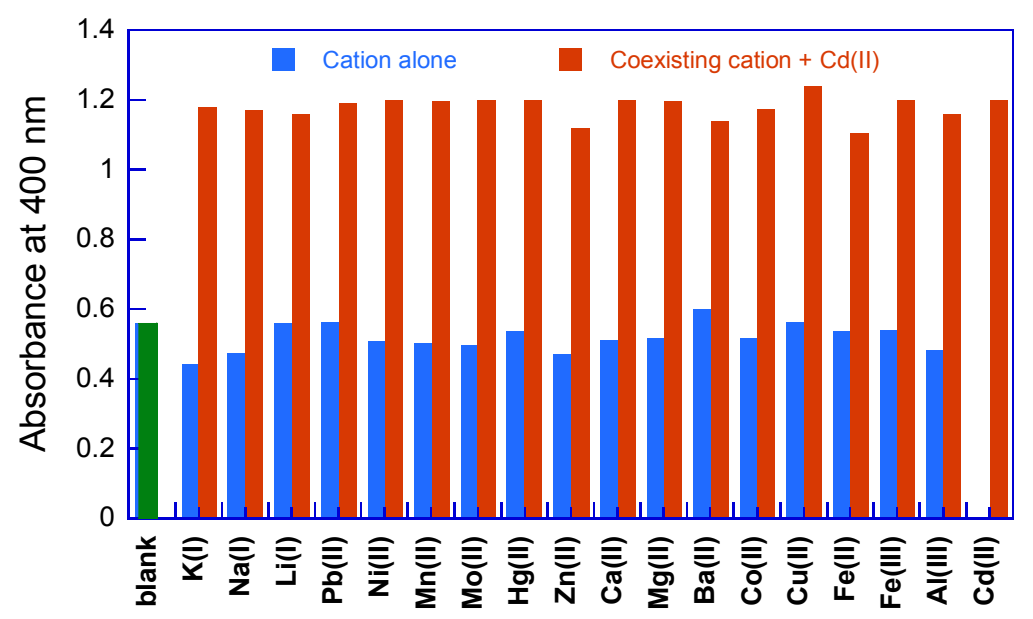

Fig. 10. Absorption intensity of the TG-CdSe QDs $\left(5 \times 10^{-4} \mathrm{M}\right)$ solution at $400 \mathrm{~nm}$ shows specificity for $\mathrm{Cd}^{2+}$ ion. Blue bars denote the response of QDs to various individual metal cations $(20 \mu \mathrm{M})$ and orange bars show the response in the simultaneous presence of $\mathrm{Cd}^{2+}(15$ $\mu \mathrm{M})$ and various coexisting ions. 
Grapical Abstract:

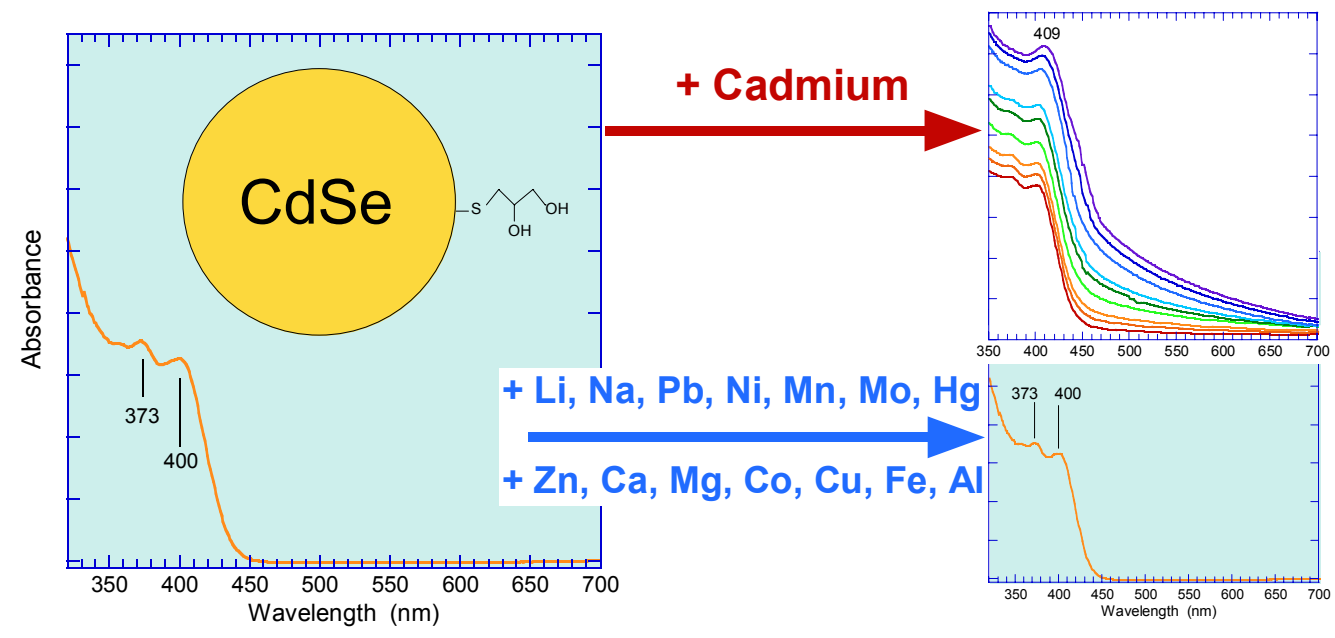

